\title{
American Educational Research Association
}

In Pursuit of the Expert Pedagogue

Author(s): David C. Berliner

Source: Educational Researcher, Vol. 15, No. 7 (Aug. - Sep., 1986), pp. 5-13

Published by: American Educational Research Association

Stable URL: http://www.jstor.org/stable/1175505

Accessed: 03/03/2010 15:16

Your use of the JSTOR archive indicates your acceptance of JSTOR's Terms and Conditions of Use, available at http://www.jstor.org/page/info/about/policies/terms.jsp. JSTOR's Terms and Conditions of Use provides, in part, that unless you have obtained prior permission, you may not download an entire issue of a journal or multiple copies of articles, and you may use content in the JSTOR archive only for your personal, non-commercial use.

Please contact the publisher regarding any further use of this work. Publisher contact information may be obtained at http://www.jstor.org/action/showPublisher?publisherCode=aera.

Each copy of any part of a JSTOR transmission must contain the same copyright notice that appears on the screen or printed page of such transmission.

JSTOR is a not-for-profit service that helps scholars, researchers, and students discover, use, and build upon a wide range of content in a trusted digital archive. We use information technology and tools to increase productivity and facilitate new forms of scholarship. For more information about JSTOR, please contact support@jstor.org. 


\title{
In Pursuit of the Expert Pedagogue
}

\author{
DAVID C. BERLINER \\ University of Arizona
}

\begin{abstract}
$\mathbf{O}_{\text {ver the past year my colleagues }}$ and I have been searching for expert pedagogues. We want to tell you why we think that it is important to engage in such a search and share with you both the problems we encountered and the fascinating side issues that were revealed as we made our search. We will present the first findings from our research and those of other scholars who also are trying to understand the nature of expertise in pedagogy.
\end{abstract}

\section{Background}

Like many others, we believe the observational, correlational, and experimental literature on research on teaching has been very fruitful. From observational and correlational findings, for example, we have determined that the presence of opening homework reviews in mathematics classes are associated with higher achievement. This idea was studied further by creating levels of review and using these levels as variables in experiments. Opening homework reviews were again confirmed as important. Re-

David C. Berliner is Professor of Educational Psychology, University of Arizona, College of Education, Dept. of Educational Psychology, Tucson, AZ 85712. His specializations are the study of teaching, teacher education, and educational policy.

This paper was the Presidential Address at the 1986 annual meeting of the American Educational Research Association in San Francisco. Dr. Berliner's colleagues on the University of Arizona research project include his co-director, Kathy Carter, and their staff and students, Kay Cushing, Jeremy George, Stefinee Pinnegar, Donna Sabers, and Pamela Stein. The Spencer Foundation of Chicago is gratefully acknowledged for the funding of this project. cent guidelines for conducting mathematics lessons in the intermediate grades, based on Good's excellent research, feature the use of such review activities (Good, Grouws, \& Ebmeier, 1983). Rosenshine elevated such findings to the level of a teaching function that must be fulfilled for effective instruction to take place (Rosenshine \& Stevens, 1986). Thus, we raised our observations, correlations, and experimental evidence to the level of a principle upon which to judge effective teaching. From another viewpoint, however, our knowledge about such findings remains very incomplete.

What is it we need to know now? We need to know under what conditions opening homework reviews are needed and when they are not needed-that is, why do teachers choose to use a homework review following some assignments and not others? We need to know what cues in classrooms speak clearly to teachers and say "Stop! Go into your review routine." We also need to know what cues during the review speak clearly to teachers and say, "Stop! This review is over."

We need to find out how some teachers use opening homework reviews to serve multiple purposes, such as informing themselves about the difficulty of the assignment, identifying the students who are not prepared, are having trouble, or who are breezing through and could easily become bored. We also need to find out how the pace and nature of subsequent instruction is affected by the information collected. We should begin to identify the subactivities within reviews that cause problems, the conditions under which some reviews break down, and the parts of the review task that can be routinized.

The point of this analysis is that a first stage of scientific investigation in a field of inquiry might be judged completely successful if what we learn is merely where to look further. In the study of teaching over the last 20 or so years, we have moved well into that first stage. But after that stage, it becomes more important to ask different questions about the phenomena that have been identified as worth looking at.

My colleagues and I have formulated a strategy to obtain that kind of information. We think we need to find and study expert and experienced teachers and compare those teachers with ordinary or novice teachers in order to search for more information about the tasks and teacher behaviors that our research community has revealed as important.

An example of this kind of second stage of inquiry is given in one of a set of groundbreaking studies of expert teachers by Leinhardt and Greeno (1986). These researchers looked at teachers' plans for lessons, the activity structures by which the plans were carried out, and the routines that were embedded in the classroom activities. These routines are shared, scripted, virtually automated pieces of action. Routines often allow students and teachers to devote their attention to other, perhaps more important matters inherent in the lesson.

In this study of the opening homework review, the expert teacher was found to be brief, taking about one-third less time than a novice. She was able to pick up information about attendance, about who did or did not do the homework, and to identify who was going to need help in the subsequent lesson. She was able to get all the homework corrected and elicited mostly correct answers throughout the activity. And she did so at a brisk pace and without ever losing control of the lesson. Routines were used to re- 
cord attendance, to handle choral responding during the homework checks, and for hand raising to get attention. The expert used clear signals to start and finish lesson segments. Interviews with the expert revealed how the goals for the lesson, the time constraints, and the curriculum itself were blended to direct the activity.

In contrast, when the novice was enacting an opening homework review, she was not able to get a fix on all who did and did not do the homework, she had problems with taking attendance, and she asked ambiguous questions that led to inadequate assessment of the difficulty level of the homework. At one time the novice lost control of the pace and never did learn which students were going to have more difficulty later on in the lesson. The novice showed lack of familiarity with well-practiced routines. There seemed to be no habitual way to act. Students, therefore, were unsure of their roles.

This work adds a new dimension to our understanding of the apparently simple classroom task called the opening homework review. Although traditional forms of observational, correlational, and experimental work focused our attention on opening homework reviews and provided us with beliefs about its utility, it is only with a microanalysis of an opening homework review task and interviews with expert and non-expert performers of the tasks that we get fresh insights about the internal criteria that might be used for judging the enactment of the task itself.

There are many other reasons we think it is important to identify and study expert teachers and to compare those teachers with less expert ones, as in the work just described. For example, because these kinds of studies give us information about the routines, scripts, and schema used by experts, we are helped in identifying the buggy routine or script, or the ill-formed schemata, that might be characteristic of less expert or novice teachers. Leinhardt and Greeno (1986) found that visual scanning and well-scripted routines were important characteristics of the opening homework review process for expert teachers. Brooks and Hawke (1985), compar- ing experienced effective with inexperienced ineffective seventh-grade mathematics teachers, found precisely the same two characteristics when they studied classroom openings. They illustrate this point about the utility of expert-novice comparisons when they conclude from their study that,

... if you had to prescribe to a junior high school teacher an apparently effective method for opening a class period, the scenario would be as follows: Develop a routine opening that features visual scanning, a quick call to order in a business-like tone of voice, a method of roll taking that is time efficient, an opening verbal sequence that includes behavioral and academic expectations, anticipate areas of confusion in explanations, and call for questions before signaling the beginning of the first activity. Threats to an efficient opening appear to include: the absence of an effective day to day behavioral routine, a slower call to order in a nonbusinesslike tone of voice, the absence of visual scanning, a procedure for taking roll that is time consuming, the inability to anticipate confusion and the absence of advanced organization. (p. 5)

Thus, we glean a bit of evidence from these two studies dealing with classroom openings and opening homework reviews in mathematics. Such evidence should influence our design of training programs for beginning teachers. The studies provide some information about what beginning teachers might want to think about when they plan for or engage in teacher activities such as openings and opening homework reviews. The performance of experts, though not necessarily perfect, provides a place to start from when we instruct novices. The experts' performance provides us, as Glaser (in press, a) has noted elsewhere, with a temporary pedagogical theory, a temporary scaffolding from which novices may learn to be more expert.

Another reason to study experts is that they sometimes provide exemplary performances from which we can learn. They can, more than most teachers, provide us with the cases - the richly detailed descriptions of instructional events-that should form a part of teacher education programs. As Shulman (1986) so eloquently argued in his 1985
AERA presidential address, beginning teachers need such cases of practice to develop their full understanding of pedagogy. What we have come to believe is that the determination of molecular weight in a chemical reaction, or the tracing of the afferent system in a frog, or the dissection of cases of classroom openings, are conceptually equivalent phenomena. They require study in laboratories uniquely designed for different professions (Berliner, 1985). If we ever do establish genuine teacher education laboratories, the exemplary performance of expert pedagogues will provide extremely useful case material for analysis by novices.

Yet another reason to study experts is to promote thinking about the nature of expert systems in pedagogy. Knowledgeable writers in that area (Lesgold, 1985; Ohlsson, in press) have pointed out that the design of an intelligent tutoring system requires versatile output. That is, expert tutoring systems need a wide range of instructional options to choose from and some decision rules about when to use these options. Expert teachers are likely to have more of that kind of knowledge than ordinary teachers.

It might also pay us to act as if we could develop expert systems in other areas of instruction. By engaging in research of the type that has led to the building of expert systems in medicine, chess, or physics we could codify, formalize, and systematize the knowledge of expert teachers (see Duda \& Shortliffe, 1983). This would be helpful even if computer versions of expert systems never become a reality for the classroom teacher outside the realm of tutorial systems. We could, perhaps, through this kind of research strategy end the lament of the many scholars (e.g., Jackson, 1968; Lortie, 1975) who have noted that teachers have no shared body of technical knowledge upon which to call.

Still another reason expert teachers make interesting subjects to study is because of a problem inherent in the student teaching experience. There is some consensus that it is the cooperating or supervising teacher who, during the student teaching experience, makes the greatest impact on the career 
development of the novice teacher. The cooperating teachers are supposed to be the models, experts, masters, mentors, coaches, and so forth, who lead the novice to some sort of competency in teaching. But a fundamental problem in apprenticeship programs is that experienced and expert practitioners very often lack the ability to articulate the basis for their expertise and skill. Schon (1983) talks about the commonly found inarticulateness of people who are themselves competent performers:

When we go about the spontaneous, intuitive performance of the actions of everyday life, we show ourselves to be knowledgeable in a special way. Often we cannot say what it is that we know. When we try to describe it we find ourselves at a loss, or we produce descriptions that are obviously inappropriate. Our knowing is ordinarily tacit, implicit in our patterns of action and in our feel for the stuff with which we are dealing. It seems right to say that our knowing is in our actions. (p. 49)

In other words, as Gilbert Ryle has put it, knowing how is a different kind of knowing than knowing that. Some of the first work on the study of expertise in pedagogy reveals that a great deal of the experts knowing-in-action is due to the automation of procedures. These are the teaching routines that were described earlier. These routines may be hardly noticeable to an expert teacher as they are hardly noticeable to expert athletes and musicians. Bloom (1986) recently described the importance of automation of procedures among the experts he studied. All of these talented individuals in sports, music, or the professions talked about the great amount of practice and training time -25 to 50 hours per weekthat they had devoted to the field in which they had succeeded by the time of their adolescence. Once their skill was developed to a high level of automaticity it could be maintained with very little practice or thought. That is the key point. Automation provides great economy of effort.

The automaticity of certain processes apparently enables people who have achieved eminence to transcend their daily existence and to rise to creative heights in their chosen field. Bloom, rightly, has resurrected the wonderful work done at the turn of the century on automaticity by the psychologist William Bryan and his student, the telegrapher Noble Harter (1899). In their studies of learning telegraphy they concluded that,

The learner must come to do with one stroke of attention what now requires half a dozen, and presently in one still more inclusive stroke, what now requires 36 . He must systematize the work to be done and must acquire a system of habits corresponding to the system of tasks. When he has done this he is master of the situation in his [professional field].... Automatization is not genius, but it is the hands and feet of genius. (p. 375)

It is likely, therefore, that studies of how expert teachers perform and think about their performance of routinized procedures will be helpful in training cooperating teachers to articulate their knowledge in ways that might truly educate their apprentices.
Another reason we study expert teachers is to influence current policy in certain states where teaching certificates are provided to people with subject matter knowledge but no teaching experience. We believe such practices ignore the complexity of teaching in the modern public school. Thus, in our research program, we compare the performance of three groups of teachers-experts, novices, and postulants (the postulants being personnel from business and industry-with mathematics and science skills and a desire to change careers and teach in public schools). This kind of comparative research might yield data to challenge some state policies about teacher certification.

Still another reason to study expert teachers is to influence state and district policies regarding master teachers. The public seems not to believe that mere number of years on the job makes a master teacher. If the public is going to continue to pay more money for these new career positions, it will ulti-

\section{National Academy of Education Spencer Fellowship Program}

Spencer Fellowships are designed to promote scholarship in the United States and abroad on matters relevant to the improvement of education in all of its forms.

\section{To Qualify:}

- Applicants must have received their PhD, EdD, or equivalent degree no earlier than January 1, 1981.

- Applications from persons in education, the humanities, or the social and behavioral sciences will be accepted; they must describe research whose relevance to education is apparent.

- Applications may be made either directly by the individual applying for the Spencer Fellowship or through nomination from a senior scholar.

- Applications will be judged on the applicant's past research record, the promise of early work, and the quality of the project described in the application.

\section{Fellowship Awards:}

- will be announced in April 1987

- fellows will receive $\$ 25,000$ for one academic year of research, or $\$ 12,500$ for each of two contiguous years working half-time

- up to twenty-five Spencer Fellowships will be awarded each year

- selection will be made by a committee composed of members of the National Academy of Education

\section{Contact:}

For further information and application forms, contact: Gail Keeley, National Academy of Education, Harvard Graduate School of Education, 108 Longfellow Hall, Cambridge, Massachusetts 02138.

Applications and all supporting material must be postmarked by January 1, 1987 for receipt no later than January 15, 1987. 
mately want some assurance from the educational community that expert or master teachers indeed exist and that they have characteristics that would distinguish them in some way from more ordinary teachers.

Finally, there is one further reason for studying expert teachers: professional pride. It would be a great boost for teachers to know that some members of their profession resemble experts in other fields, such as grand masters in chess, internationally regarded bridge players, or highly reputed physicists.

\section{Problems in Studying Expertise}

Having elaborated on why we should study expert teachers, we must now confess that our preliminary forays into the nature of expertise in pedagogy have been hampered by a number of problems. First, of course, are the methodological problems associated with think-aloud and stimulated recall protocols and with other contemporary forms of introspection. Reading such protocols and diagramming the propositional knowledge of teachers is, to the old-fashioned behaviorists on the project, a bit like reading Rorschachs produced by someone speaking BASIC! Nevertheless, interesting data do emerge when one studies the performance of people of different degrees of experience and expertise and also ask them to tell you what they are seeing, thinking, doing, and feeling.

We will leave these methodological problems to others to debate because they are not nearly as important as three other problems we have encountered. The first has to do with finding criteria for defining expertise in pedagogy. The second deals with the confounding of experience and expertise. The third problem has to do with stipulating which knowledge systems should be studied in exploration of pedagogical expertise. A brief comment on each of these issues follows.

\section{Criteria for Identification of Experts}

The grand master in chess, of course, has won thousands of games against tough opponents. Points and wins are accrued over time. In the same way an Olympic champion is accorded his or her gold medal. In such cases agreement about who is and is not an expert is easy to obtain. There are less objective records of performance by which to judge expert physics and mathematics problem solvers. Nevertheless, experienced teachers of advanced mathematics and physics, in comparison to beginning graduate students, are ordinarily accorded expert status in our society without much dissension.

In the elementary grades a teacher's reputation, along with classroom observations and consistent excellent classroom performance on standardized tests, may be taken as indicators of expertise despite all the well-known faults inherent in reputational measures, observation, and standardized tests. In mathematics and science teaching at the junior and senior high school level, where we have chosen to look for experts, we have much more difficulty. Students may have five or more teachers per day, and standardized testing may not occur annually, or may not be tied clearly to a particular course. What this means, of course, is that the identification of expert teachers in the upper grades is a problem. We are not sure we have satisfactorily solved it, but we have used reputation, classroom observations by three independent observers, and performance in our laboratory tasks to build a pool of interesting, experienced informants whom we call experts.

We did, however, try to use one external and independent criterion to identify experts. We thought we might use the nominees for teacher of the year in various states to learn about expert pedagogues. ${ }^{1}$ The national teacher of the year program is sponsored by the Council of Chief State Schools Officers and two commercial publishers. The guidelines for the contest state that the program is designed to reward excellence in teaching. The winner of the annual competition often receives some prizes and is honored at a White House ceremony. Each of the states submits their state candidate to the national committee, which reminds each state that their search is "for those who exemplify the finest in the profession" and who will "represent good teachers everywhere." They go on to say, however, that it is not a search for the best teacher in the country-a fact that will soon become painfully obvious.

The national screening committee assumes that the states will pick the best candidates. But an analysis of how teachers are selected in the sample of states we have examined reveals such interesting findings that in most states some of the judges of teachers are parents. The judging panels routinely contain university professors, state legislators, student representatives, representatives from school boards, and representatives from business and industry. In at least one state the judge is from Better Homes and Gardens magazine. In only $30 \%$ of the states were past teachers of the year automatically assigned as judges.

In most states the judges are rotated each year. Only a few of the states provided any training for their judges, and when training was provided it was usually for half of one day. In one state, we were told, an important criterion for judging a nominee was church work. One state coordinator could not tell us whether they ever interviewed the candidates or not. Another state coordinator said it was not worth the time to observe the candidates. This competition has been going on in roughly the same manner for 35 years.

The judges on the national committee, representing national organizations in education, review portfolios prepared by the state's nominee. These include a fact sheet, a biographical sketch designed to emphasize the teacher's early life and reasons for going into teaching, a statement of philosophy about teaching, a listing of professional development courses and experiences, and a listing of the philanthropic and civic organizations to which the nominee for the teacher of the year has contributed. In our interviews with coordinators of the program we were told that the major criterion for teacher of the year is that the teacher like children.

From materials containing virtually nothing that would, from our 
perspective, reveal much about expertise in classroom teaching, four finalists are picked by the panel of judges. The finalists are then visited and interviewed. The interview is videotaped. The finalists are observed briefly in their classrooms. The colleagues of the nominees are also briefly interviewed. This crucial visit and interview are done by a representative of Good Housekeeping magazine, one of the sponsors of the competition. These data are sent back to the judges and a winner is selected.

We have had, personally, some very productive interactions with state and national teachers of the year. We have absolutely no doubt that they are articulate, poised, interesting human beings with opinions about teaching that should be taken very seriously. Whether they are anything but that is a question that should be raised for the whole profession to consider.

We also compared the judging of the finest teachers in our country with judging in some other areas that society values. We learned that to become a livestock judge in Arizona you ordinarily have to take a year of livestock evaluation courses at a college. Most people taking such formal coursework have had years of practice in judging at $4-\mathrm{H}$ Clubs and at Future Farmers of America clubs before entering the college program, and they compete in judging at the college in order to begin to earn a reputation as a judge. Some colleges actually recruit judges. Team competition between colleges in judging occurs. The University of Arizona recently placed 5th in horse judging and 13th overall in judging animals. Schools like Oklahoma State and Texas A\&M have their judging teams practice four to five hours per day before a judging competition.

We also looked at judging in other fields. The American Kennel Club's application for a judge requires 10 years of documented experience in the field. In addition, the candidates for judge must themselves have raised four litters and produced at least two champions out of these litters. Written testing and an oral interview are also required for a judgeship. The names of all new candidates who are to be awarded credentials as judges are published in the Gazette of the Kennel Club so that interested persons can offer their opinions about the applicant's qualifications. In Olympic judging it takes considerable time and money to perfect one's skills. In gymnastics and synchronized swimming it takes about 7 years to be considered a first-rate judge. In figure skating it can take 10 to 15 years.

In sum, judging livestock, crops, dogs, and athletes takes years of practice. University training is often provided. Competitive testing of judges is commonplace. And the personal qualifications of the judges are scrutinized carefully. The honorable profession of education would be lucky if it could become $10 \%$ as rigorous as the judging of livestock, potatoes, poultry, and figure skating. Currently, with annual turnover of untrained, inexperienced judges who are often older adults from other professions, we can expect an image of teaching that is archaic, stereotypical, and incomplete, and therefore inadequate to judge contemporary classroom teachers. So much for our search for an outside criterion to identify expert pedagogues.

\section{The Confounding of Experience and Expertise}

Another problem we encountered occurred because mere experience is simply not believed by most people to correlate highly with expertise in pedagogy. Perhaps this is because our problems are so illstructured. Perhaps it is due to the lack of external criteria. But for whatever reason, the problems of studying expertise in pedagogy are harder than in some other fields because of the widespread belief that we need to separate expertise from experience and to study how experience changes people without necessarily turning them into experts. This is not easy. Thus, the terms "experienced" and "expert" are used throughout this discussion as if they are interchangeable. We know they are not, but cannot yet untangle them, so we must ask for patience in resolving this situation.

\section{The Knowledge Systems Used in Pedagogy}

Another of our problems has to do with understanding what domains of knowledge are used by expert teachers in accomplishing their tasks. To study expertise in physics one studies the experienced individual's solutions to physics problems. There seems to be some kind of oneto-one correspondence between the knowledge possessed and the display of that knowledge in solving the problems (see Chi, Glaser, \& Rees, 1981). Classroom teaching seems to us to be more complicated. We have more difficulty in understanding what knowledge domains are required for successful classroom performance. Some scholars argue that only subject matter knowledge is important; others report that a teacher's personal knowledge of self is the key to understanding pedagogy (e.g., Lampert, 1984). One scholar (Elbaz, 1981) has identified dozens of domains of knowledge that are drawn on by teachers to accomplish their tasks.

We have decided from observation and reflection that two large domains of knowledge must be readily accessed to be an expert pedagogue. We have stipulated those two domains of knowledge to be subject matter knowledge and knowledge of organization and management of classrooms. The integration of these is what we ordinarily see when we observe public school classroom teaching. This conception is noteworthy, in part, because it implies that the problems faced by classroom teachers are so complex, compared to the problems faced by physics, mathematics, and chess problem solvers, that at least two complex and extensive knowledge domains must be integrated at all times to teach in contemporary American public schools. To be an expert public school classroom teacher is, we think, much harder than to be an expert physics problem solver.

\section{Studying the Expert Pedagogue}

Our goal at Arizona is to try and understand how knowledge about the running of classrooms is influenced by experience and expertise. We are concerned about the nature of the knowledge that changes a person from being a subject matter knower to a subject 
matter teacher. It is this domain of knowledge about classrooms, sometimes called practical knowledge, that is often least valued in society. Perhaps if the complexity of problem solving in that domain were made more explicit, there would be some increase in valuing the job of classroom teacher.

Already our work is beginning to yield some findings suggesting that our experts possess a special kind of knowledge about classrooms that is different from that of novices and postulants, and of a very different order than is subject matter knowledge. For example, in one of our first studies, we asked experts, novices, and postulants to look over some class records of tests, textbooks, student record books, and student information cards prior to teaching that class the following week. In this simulation, many of our experienced teachers paid virtually no attention to the student information cards. Most of our postulants and many of our novices acted like they had to make sense out of all the information provided. Postulants, in particular, concentrated on the student information cards. Some of our expert teachers commented that they really did not want to know anything about the children. They intended to negotiate their own relationships with each child. Furthermore, in a sense, they believed they already knew all about them. They did not have to delve very long into the assorted class records before deciding that these students were "like other kids."

Our finding apparently replicates one by Calderhead (1983), who noted that experienced teachers seemed to have a different schemata than novice teachers for students. Calderhead used interviews and the repertory grid technique to study experienced, student, and novice teachers. He reported that the experienced teachers seemed to know the different home backgrounds of students, they knew what to expect in the way of knowledge and skills in their classrooms, they had an image of the likely number of students who would need help, and they had an image of the types of behaviors and discipline problems that could be expected. They knew what the students might possess in the way of previous experience, skills, and knowledge. And the teachers had a sense of what kinds of activities the children engaged in outside of school.

As Calderhead put it, the experienced teachers had amassed a large quantity of knowledge such that they did, in a sense, know their new class even before they got to meet them. This knowledge influences how subject matter will be considered, but is in fact an image or knowledge of classrooms that is a separate kind of knowledge. It is a knowledge that influences the running of the classroom: the pace, the level of intellectuality, affect, work orientation, and so forth. It is knowledge that influences classroom organization and management and is the basis for transforming subject matter. Such knowledge is complex, often tacit, derived from experience, and worthy of being called expert knowledge in most other fields of endeavor.

In fact, a number of features of experts have recently been described by Glaser (in press, a; in press, b; see also Chi, Glaser, \& Farr, in press). These features are drawn from studies of physics and mathematics problem solvers, chess masters, expert bridge players, radiologists, and many others. Our work was first designed to look at expert teachers in relation to this list. What we have found from our own research and from reviewing the studies of others, as they relate to the general characteristics of experts, is discussed next.

It is said that novices in many fields hold literal views of objects and events whereas experts make inferences about those objects and events. In one of our studies small groups of experts, novices, and postulant teachers viewed for the briefest moment a slide of a classroom. They were then asked what they saw. On one slide a postulant, that is, a scientist from industry, saw "a blonde-haired boy at the table, looking at papers. Girl to his left reaching in front of him for something. Other activity in classroom." When viewing the same slide, our novice, a first-year teacher, saw "a room of students sitting at tables." Another novice viewing the same slide saw "a classroom. Student with back to camera working at a table."

In contrast to these literal descriptions, one of our experts viewing the same slide, with the same brief exposure said, "It's a handson activity of some type. Group work with a male and female of maybe late junior high school age." A second expert reported, "It's a group of students maybe doing small-group discussion on a project as the seats are not in rows." Thus, as in other fields, expert teachers are making inferences and not literally reporting what they see. They are applying their domainspecific knowledge to make sense of the classroom they are viewing. Our novices and postulants, for the most part, can do nothing more than describe the surface characteristics of the classrooms.

It is also said that experts categorize problems to be solved at some kind of higher level, whereas novices classify problems to be solved by the surface characteristics given in the problem. In one of our studies by Gail Hanninen (1985), a University of Arizona student, realistic scenarios about gifted children were written. For example, one scenario described Mark, an 8-yearold Oriental boy with severe hearing defects who likes mathematics and science and who has strong interest in computers. Scenarios of this type were administered to 15 subjects. Five of the subjects were experts, experienced teachers of the gifted; another five were equally experienced teachers but without any background in gifted education; and five more were novice teachers of the gifted, still working on their certification.

Let us examine just the opening sentence of some protocols. From one novice: "Mark seems like a very talented individual with many diverse interests." Another novice: "Mark should be encouraged by his teacher to continue his science experiments and work on the computer." From an experienced teacher who was a novice in the area of gifted education: "He should be able to pursue his interests in greater depth." In contrast to these begin- 
ning essays of ways to meet Mark's needs, in which surface characteristics of the problem were used, one expert began right off with: "Mark's needs can be broken into three broad areas: academic enrichment, emotional adjustment, and training to cope with his handicap."

As in other fields, the experts used higher order systems of categorization to analyze the problem they faced. We would argue, of course, that classifying a problem as solvable by Newton's second law or as a conservation of energy problem, is no different than classifying Mark's educational needs as falling into three categories and describing action relevant to each of those categories.

It is also said that experts have extraordinarily fast and accurate pattern recognition capabilities. These recognition skills appear to act like schema instantiations. The recognition of patterns reduces the cognitive processing load for a person. Sense is instantaneously made of a field, such as a chess board. Quick pattern recognition allows an expert chess player to spot areas of the board where difficulties might occur. Novices are not as good at recognizing such patterns, and when they do note them they are less likely to make proper inferences about the situation.

We obtained a protocol related to this characteristic of experts. In our task, called the Look Again Task, subjects view a slide briefly and describe what they see. Then they see the slide again, briefly, and then see it briefly for a third and final time. With each viewing they update information and tell us what new things they see. One expert in science, after the second viewing of a slide, said: "It's not necessarily a lab class. There just seemed to be more writing activity. There were people filling out forms. It could have been the end of a lab class after they started putting the equipment away..." After the third viewing of the slide, the expert said, "Yeah-there was...very little equipment out and it almost appeared to be towards the end of the hour. The books appeared to be closed. Almost looked like it was a clean-up type of situation."

Novices did not usually perceive the same cues in the classroom and could not, therefore, make the inferences that guided the expert's understanding of the classroom. The expert, by the way, was absolutely correct. It was a clean-up kind of activity. We regard the reading of a classroom, like the reading of a chess board, to be in part a pattern recognition phenomenon based on hundreds and thousands of hours of experience. As an example, we present excerpts from another protocol with the Look Again Task that illustrates how lengthy experience influences perception. A mathematics class was viewed. The expert mathematics teacher said, "The first time I saw a student raising his hand in the classroom and I subconsciously, apparently, was looking for the teacher and I did not notice the teacher in the classroom the first time. The second time I was curious. I was still looking for the teacher and didn't see the teacher. The third time I saw some students that were apparently seated in such a way that they were facing another direction of the classroom. It was an unusual seating arrangement. My impression was that part of the class was facing one direction and another part of the class was facing another direction." Some of our experts, but very few of our novices and postulants, seemed to have this kind of sensitivity to perceptual information.

It is also said that experts may be slower than novices in initial stages of problem solving. They seem to take longer to examine a problem, to build a problem representation, or to think through first strategies. In our study of the teachers of the gifted (Hanninen, 1985) we found that the mean time for a novice to read through a scenario and begin writing about ways to help deal with a particular child was 2.6 minutes. The experienced teachers, who had no background in gifted education, took 3.0 minutes. The mean time for the experienced teachers of the gifted, our experts, was $9.8 \mathrm{~min}$ utes. That is, from the start of reading their problem through the start of presenting their solution, it took them three or four times as long as the two groups of novices, a pattern similar to what happens in other fields of study.
It is also said that the experts are sensitive to the task demands and the "social structure" of the job situation. An example of this in the area of teaching is provided by Housner and Griffey (1985), who studied experienced and inexperienced physical education teachers. During instructional planning, five of the eight experienced teachers asked to see the facilities in which they would teach. None of the eight novice teachers made such a request. We believe this to be an example of how experts are unusually sensitive to the characteristics of the situation in which their work is to be done.

In some domains experts have been shown to be "opportunistic planners." They are quick to change tracks. An example of this was found in Housner and Griffey's (1985) teachers as they planned physical education instruction. The authors found that "inexperienced teachers exhibited a functional fixedness when considering the uses of equipment. Experienced teachers, however, employed equipment in many ways that were different from traditionally accepted uses" (p. 48). In the use of equipment, then, the experienced teachers seemed to be more opportunistic than the novice teachers.

It is also said that experts show self-regulatory or meta-cognitive capabilities that are not present in less mature or experienced learners. Among the meta-cognitive capabilities are skill in planning and using time sensibly. In Leinhardt and Greeno (1986), we find one of their expert teachers illustrating such meta-cognitive skill when she says, “... I don't have this written down anywhere, but in my mind, I have it. I'm going to be finished with fractions before Christmas. I have to be, you know, to get on. So I'll just pace myself now so that I will get finished"' (p. 88).

An example of skillful planning also shows up in the Housner and Griffey (1985) study. Experienced teachers were better able to anticipate situations that were likely to be encountered and were able to generate contingency plans based on those possibilities. In fact, about 1 out of 5 of the instructional strategy decisions of experienced teach- 
ers had to do with adaptations of instruction in case the planned lesson did not work out. That rate was about 1 out of 10 for novices.

It is also said that expertise is developed only over long periods of time, say hundreds, perhaps thousands of hours of learning and experience. Precisely that kind of time frame for learning about running classrooms has been reported by Huberman (1985). His inquiry was designed to find out when experienced teachers actually mastered the problems that had perplexed first-year teachers. Problems of discipline, effectiveness with both slow and rapid students, sustaining the interest of poorly motivated students, having a variety of materials that students liked to work with, and establishing a satisfactory set of requirements for the classroom were all judged as being accomplished in no less than 5 years for the majority of the teachers. Only five of the original 18 problems of first-year teachers were adequately solved by the majority of teachers in less than 3 years. Thus, we see lengthy experience as necessary to solve problems of classroom organization and management in sensible ways.

It is also said that an expert's unique knowledge shows up in relation to the goal structure of a problem. In our simulation requiring preparation for taking over a class, our expert, novice, and postulant teachers examined information about students, homework, texts, and tests. One expert, in looking at the homework remarked, "The student that had four incorrect really understood it better than the students that had two incorrect answers because of the questions he missed. The way he missed his, he really got the concept. He missed partial problems.... [He] had a better understanding of the chapter and so I think he could have helped most students. . because he did understand those story problems."

It appeared to us, in studying the protocols of experts, that they often seemed to "look inside" student work to pull out what was important to guide lesson planning, their major goal. On the other hand, that kind of analysis of homework or test performance to guide lesson plan- ning was usually missing when novices or postulants were questioned. The comments of postulants, in particular, were noticeably vague and largely unrelated to any action plans for working with students or curriculum.

As in other studies of expertise, our expert pedagogues seemed to represent problems differently than did novices. One such problem, posed to experts, novices, and postulants was to plan the first two lessons for a class that they were to be taking over. Most of the experts saw the problem as consisting of two integral parts: finding out what students already knew and starting the classroom over from scratch. The experts also had established routines to introduce themselves, explain new rules, get lots of student information, and to "groove" the students.

You may remember Geoffrey's actions in starting the school year, as described by Smith and Geoffrey (1968) in their book on teaching in an urban classroom. Geoffrey gave students relatively innocuous tasks to carry out, so that he could gently, firmly, but quickly establish that teachers give orders while students carry orders out. That was called "grooving" the students. Our experts had almost all learned to groove the students, though none of them had a label for that kind of knowledge.

Furthermore, in this situation, the experts all made much out of starting the class over. New rules and new instructional systems were seen as needed. New relationships had to be established. Postulants in this task were for simply moving on-taking the old material and lessons and getting the class moving on in the tracks of the old teacher. This course of action, we all believed, was bound to become a problem somewhere down the road. The postulants seemed to want to know where the class was, and not what the students knew.

Our novices in this problem seemed to be closer to experts in their planning but not as clear about their goals. Although they saw the need to introduce themselves and explain their ideas about management and subject matter, they did not see as clearly the need for a new start the way the experts did. And although they planned for reviews to get student information, just like the experts, the review apparently was seen as something like a homework check, a chance for the novice teacher to correct student errors. The experts planned to use their review procedures to probe student knowledge in order to guide instruction. This is a subtle but, we think, important difference in the two groups.

In this simulation, as expected, our novices and postulants usually worried more about discipline and management than did our experts. The experts appeared to be so confident in that area that they were unconcerned about management and discipline when planning instruction. This kind of confidence allowed one expert teacher to plan for a personal talk with the class about his beliefs, hopes, ambitions, and the like in order to purposely be "vulnerable" in front of them. His confidence in his management skills allowed his humaneness to be featured in his introduction. We do not think novices and postulants could have dared to be so open about themselves in their planning of introductory activities with their students.

\section{Conclusion}

On the basis of the work we have started, we feel assured that at least some experienced teachers some of the time act like experts in other fields, and that the comparative analyses of expert, novice, and postulant teachers are worth continuing. Among the most important reasons to continue this work is the chance to boost teachers' pride in their profession.

The studies of experts have already given us cases of which to be proud. The superb performance of Ms. Patrick, the expert teacher of subtraction with regrouping studied in Pittsburgh by Leinhardt (1985) is one such example. The 8-day orchestration and conduct of those lessons with 25 low-income children is, to us, a much more monumental feat than the orchestration and conduct of a four-movement symphony. But it is only a more monumental feat if we choose to see it that way. 
We sometimes seem to have problems with our perception of teachers' skillfulness, categorizing it as mere practice. We often confuse the cognition necessary for exemplary performance with the validity of the course of action. When an expert physics problem solver takes time and announces that the problem involves Newton's second law, he or she is an expert. When an experienced teacher takes time and classifies a child's learning problems into three categories that lead to a particular set of actions, it is often considered to be an example of something less. We make a great mistake if we confuse the validity of the inferences with the inference making process. We would argue that the cognitive processes required for classifying problems and positing solutions are the same for the very experienced physicist and the very experienced teacher. In fact, we will gladly go further out on a limb and argue that in the ill-structured domains (see Voss \& Post, in press), where surity about right action does not exist, the choice of a sensible solution strategy for a problem is an even more complex task than is solving problems in well-structured domains such as mathematics, radiology, or chess.

Practical problem solving, it seems, has a kind of low-class reputation. Because the sources of professional knowledge for a teacher are highly bound by time, materials, and place we call it practical knowledge. But it now appears that such domain-specific knowledge is a characteristic of every kind of expert. In other fields we honor such knowledge. In education, it is merely practical, and what is often implied is that such knowledge is less complex, less understandable, or less amenable to scientific study.

Buchmann (1983) has commented on the practical thinking of teachers: "We have no reason to assume that premises that need to be guessed at, terms without clear definitions, oblique references, and beliefs that are debatable must be associated with wrong headed ideas or indefensible lines of action" (p.12). We agree completely, adding only that expert teachers are one of the best sources to see and study examples of defensible action, and that the knowledge gained from such study is much more codifiable than many people think.

We will continue our pursuit of the expert pedagogue. If we ever feel really secure that we have found a few of these elusive beasts, we will study them in great depth and share those findings with those who also await their capture. Like the search for the Yeti and for Bigfoot, we expect to have a good many false sightings and a good deal of fun along the way.

\section{Notes}

${ }^{1}$ Bonnie Woodin, a University of Arizona graduate student, conducted the research discussed in this section. We are grateful for her help.

\section{References}

Berliner, D.C. (1985). Laboratory settings and the study of teacher education. Journal of Teacher Education, $36,2-8$.

Bloom, B. (1986, February). Automaticity. Educational Leadership, 70-77.

Brooks, D.M., \& Hawke, G. (1985, April). Effective and ineffective sessionopening teacher activity and task structures. Paper presented at the annual meeting of the American Educational Research Association, Chicago.

Bryan, W.L., \& Harter, N. (1899). Studies of the telegraphic language: The acquisition of a hierarchy of habits. Psychological Review, 6, 345-375.

Buchmann, M. (1983). Argument and conversation as discourse models of knowledge use. Occasional Paper No. 68. East Lansing: Michigan State University, Institute for Research on Teaching.

Calderhead, J. (1983, April). Research into teachers' and student teachers' cognitions: Exploring the nature of classroom practice. Paper presented at the annual meeting of the American Educational Research Association, Montreal.

Chi, M.T.H., Glaser, R., \& Farr, M. (in press). The nature of expertise. Hillsdale, NJ: Erlbaum.

Chi, M.T.H., Glaser, R., \& Rees, E. (1981). Expertise in problem solving. In Advances in the psychology of human intelligence (Vol. 1). Hillsdale, NJ: Erlbaum

Duda, R.O., \& Shortliffe, E.H. (1983). Expert systems research. Science, 220, 261-268.

Elbaz, F. (1981). The teacher's "practical knowledge": Report of a case study. Curriculum Inquiry, 11, 43-71. Glaser, R. (in press, a). On the nature of expertise. In Proceedings of the In Memorium Hermann Ebbinghaus Symposium. Amsterdam, The Netherlands: Elsevier-North Holland Publishers.

Glaser, R. (in press, b). On the nature of expertise. In C. Schooler \& W. Schaie (Eds.), Cognitive functioning and social structure over the life course. Norwood, NJ: Ablex.

Good, T.L. Grouws, D.A., \& Ebmeier, H. (1983). Active mathematics teaching. New York: Longman.

Hanninen, G. (1985). Do experts exist in gifted education? Unpublished manuscript, University of Arizona, College of Education, Tucson.

Housner, L.D., \& Griffey, D.C. (1985). Teacher cognition: Differences in planning and interactive decision-making between experienced and inexperienced teachers. Research Quarterly for Exercise and Sport, 56, 45-53.

Huberman, M. (1985). What knowledge is of most worth to teachers? A knowledge-use perspective. Teaching and Teacher Education, 1, 251-262.

Jackson, P.W. (1968). Life in classrooms. New York: Holt, Rinehart \& Winston.

Lampert, M. (1984). Teaching about thinking and thinking about teaching. Journal of Curriculum Studies, 16 . 1-18.

Leinhardt, G. (1985, April). The development of an expert explanation: An analysis of a sequence of subtraction lessons. Paper presented at the annual meeting of the American Educational Research Association, Chicago.

Leinhardt, G., \& Greeno, J.G. (1986). The cognitive skill of teaching. Journal of Educational Psychology, 78, 75-95.

Lesgold, A.M. (1985). Computer resources for learning. Peabody Journal of Education, 62(2), 60-74.

Lortie, D. (1975). Schoolteacher. Chicago: University of Chicago Press.

Ohlsson, S. (in press). Some principles of intelligent tutoring. Instructional Science.

Rosenshine, B., \& Stevens, R. (1986). Teaching functions. In M.C. Wittrock (Ed.), Handbook of research on teaching, 3rd ed. (pp. 376-391). New York: Macmillan.

Schon, D. (1983). The reflective practitioner. New York: Basic Books.

Shulman, L.S. (1986). Those who understand: Knowledge growth in teaching. Educational Researcher, 15(2), 4-14.

Smith, L.C., \& Geoffrey, W. (1968). The complexities of an urban classroom. New York: Holt, Rinehart \& Winston.

Voss, J.F., \& Post, T.A. (in press). On the solving of ill-structured problems. In M.T.H. Chi, R. Glaser, \& M. Farr (Eds.), The nature of expertise. Hillsdale, NJ: Erlbaum. 